\title{
Stability and activity of lactate dehydrogenase on biofunctional layers deposited by activated vapour silanization (AVS) and immersion silanization (IS)
}

\author{
Jorge Nieto-Márquez Calvo ${ }^{a, b}$, Manuel Elices ${ }^{a, b}$, Gustavo Guinea ${ }^{a, b, c}$, José Pérez- \\ Rigueiro $^{\mathrm{a}, \mathrm{b}, \mathrm{c} .}{ }^{*}$, María Arroyo-Hernández ${ }^{\mathrm{a}, \mathrm{b}, \mathrm{d}}$.
}

\author{
${ }^{a}$ Centro de Tecnología Biomédica, Universidad Politécnica de Madrid, 28223, Pozuelo de Alarcón, Madrid, Spain \\ ${ }^{b}$ Departamento de Ciencia de Materiales, ETSI Caminos, Canales y Puertos, Universidad Politécnica de Madrid, \\ 28040, Madrid, Spain \\ ${ }^{c}$ Biomedical Research Networking Center in Bioengineering, Biomaterials and Nanomedicine (CIBER-BBN), Madrid, \\ Spain \\ ${ }^{d}$ (present adress) Universidad Francisco de Vitoria, 28223, Pozuelo de Alarcón, Madrid, Spain. \\ *Corresponding Author. \\ Keywords: Surface modification, Activated Vapor Silanization, Infrared Spectroscopy, Protein Adsorption, Langmuir \\ model
}

\section{Abstract:}

The interaction between surfaces and biological elements, in particular, proteins is critical for the performance of biomaterials and biosensors. This interaction can be controlled by modifying the surface in a process known as biofunctionalization. In this work, the enzyme lactate dehydrogenase (LDH) is used to study the stability of the interaction between a functional protein and amine-functionalized surfaces. Two different functionalization procedures were compared: Activated Vapour Silanization (AVS) and Immersion Silanization (IS). Adsorption kinetics is shown to follow the Langmuir model for AVS-functionalized samples, while IS-functionalized samples show a certain instability if immersed in an aqueous medium for several hours. In turn, the enzymatic activity of LDH is preserved for longer times by using glutaraldehyde as crosslinker between the AVS biofunctional surface and the enzyme.

\section{Introduction.}

The interaction between materials and biological systems depends critically on processes that occur at their interface. This interaction is especially relevant for biomaterials, since it determines the fate of the implant inside the organism[1-3]. In this regard, it is assumed that the type and state (native or denatured) of the adsorbed proteins on the surface immediately after implantation and their subsequent recognition by specific cell lineages [2] determines the response of the organism to the material. In addition to its relevance for controlling the biocompatibility of biomaterials, the adequate interaction between surfaces and biological moieties is also essential in fields such as biosensors [4,5] and for the development of drug delivery systems[6,7].

One of the basic approaches that intends to exert a tight control on the molecular events developing at the interface is the chemical modification of the material surface, a process known as biofunctionalization $[8,9]$. Surface biofunctionalization is typically performed through 
the deposition of functional groups on the surface of the material that, in most cases, allows the covalent binding between the material and selected biological molecules.

Among the main biofunctionalization techniques, the attachment to the surface of amino groups $\left(-\mathrm{NH}_{2}\right)$ by exposing the material to organometallic moieties is one of the most commonly used. The organometallic 3-aminopropylethoxysilane (APTES) is very often used as source of amines. In particular, biofunctionalization by silanization [10-12] implies the formation of siloxane bonds (Si-O-Si) between hydroxyl $(-\mathrm{OH})$ groups present at the surface and hydrolyzed organometallic molecules that carry the amino group. This technique is mostly performed in solution (immersion silanization, IS), and requires the presence of free hydroxyl groups at the surface that can react with the organometallic molecules. In order to increase the density of $-\mathrm{OH}$ groups on the surface, immersion in an acid solution (such as HFisopropanol) is commonly used in a step known as activation $[13,14]$. However, silanization processes tend to be very sensitive to the initial activation step, as well as to different environmental conditions, such as humidity, which leads to a relatively low reproducibility of the functional film properties [15], and even to the formation of aggregate structures (colloids).

In this work, the use of an alternative biofunctionalization technique, Activated Vapour Silanization (AVS) [16-18], is explored for creating a reliable interface between the material and the biological system. AVS combines vapour silanization with chemical vapour deposition (CVD) and allows an accurate control on the properties of the functionalized materials. In particular, it has been found that the surface roughness and surface amine concentration of the AVS functionalized samples can be controlled by varying the deposition conditions [19]. Since successful biofunctionalization implies that the biological molecules must preserve their function, both techniques (IS and AVS) are assessed by studying their interaction with the enzyme lactate dehydrogenase (LDH) in terms of the adsorption kinetics, amount and activity of the adsorbed protein. An important difference is detected between both functionalized surfaces, since AVS layers are shown to remain stable in an aqueous buffer at longer times than IS layers. The activity of the protein is further extended on AVS layers if glutaraldehyde is used as crosslinker between the surface and the enzyme.

\section{Materials and Methods}

\subsection{Sample Preparation}

Functionalization was performed on (100), p-type, one side polished, silicon samples with an area of $\approx 0.6 \mathrm{~cm}^{2}$. Before functionalization, silicon samples were cleaned by subsequent sonication in acetone and isopropanol, 2 minutes in each solvent, and dried with argon.

\subsection{Immersion Silanization (IS)}

Before functionalization, silicon samples were immersed for 10 minutes in an HF-isopropanol $(10 \%)$ solution in order to remove the native oxide layer of the silicon (surface activation). The samples were then immersed in $1 \%(\mathrm{v} / \mathrm{v})$ of 3-aminopropyltriethoxysilane (APTES, $\mathrm{NH}_{2}\left(\mathrm{CH}_{2}\right)_{3} \mathrm{Si}\left(\mathrm{OC}_{2} \mathrm{H}_{5}\right)_{3}$, Sigma-Aldrich) in toluene, previously heated at $103{ }^{\circ} \mathrm{C}$, for 30 minutes. The samples were subsequently sonicated after functionalization in acetone and isopropanol, 2 minutes in each solvent, and dried with argon.

\subsection{Activated Vapor Silanization (AVS)}


A detailed description of the AVS process can be found elsewhere[17,18].Briefly, APTES is placed in a low vacuum chamber and evaporated at a controlled evaporation temperature $\left(T_{\text {evap }}\right)$. The vapor is transported by an Ar flux and activated at high temperature $\left(T_{\text {act }}\right)$ before impinging on the silicon samples that are placed in the deposition chamber. Previous works[19] have demonstrated that biofunctional layers with optimum properties on silicon are obtained with deposition parameters: $\mathrm{T}_{\text {evap }}=150{ }^{\circ} \mathrm{C}, \mathrm{T}_{\text {act }}=750{ }^{\circ} \mathrm{C}, \mathrm{P}_{\mathrm{Ar}}=1 \mathrm{mbar}$ and 20 minutes deposition time. After functionalization, the samples were subsequently sonicated in acetone and isopropanol, 2 minutes in each solvent, and dried with argon.

\subsection{Enzyme immobilization}

Lactate dehydrogenase (LDH) adsorption: The amine functionalized films (by either IS or AVS) were immersed in $1 \mathrm{ml}$ of Tris- $\mathrm{HCl}$ buffer $(0,1 \mathrm{M} ; \mathrm{pH} 6,8)$ for one hour for surface passivation. Subsequently, surfaces were incubated with $600 \mu \mathrm{l}$ of bovine muscle LDH (EC 1.1.1.27; $\mathrm{P}_{\mathrm{M}}=$ $36598 \mathrm{Da}$; Sigma-Aldrich) with different concentrations $(1-80 \mu \mathrm{g} / \mathrm{ml})$ in Tris-HCl buffer $(0.1 \mathrm{M}$; $\mathrm{pH}=6.8$ ) for different times (15 min - 24 hours). After incubation, the samples were washed with $1 \mathrm{ml}$ of Tris- $\mathrm{HCl}$ buffer solution.

Lactate dehydrogenase (LDH) immobilization with glutaraldehyde: AVS functionalized samples were immersed for 3 hours in $1 \mathrm{ml}$ of phosphate buffer saline ( $\mathrm{PBS}, 1 \mathrm{x}, \mathrm{pH}=7.5$ ) for surface passivation. Later, samples were incubated for 4 hours in $1 \mathrm{ml}$ of glutaraldehyde $\left(\mathrm{OHC}\left(\mathrm{CH}_{2}\right) \mathrm{CHO}\right.$; Sigma-Aldrich), diluted in PBS at a concentration of 2,5\%. Subsequently, samples were washed for 1 hour with $1 \mathrm{ml}$ of PBS buffer and, finally, incubated for 24 hours with $600 \mu$ l of bovine muscle LDH (EC 1.1.1.27; Sigma-Aldrich) at a concentration of $50 \mu \mathrm{g} / \mathrm{ml}$ in PBS buffer.

\subsection{Enzymatic Assay}

Enzymatic Assay: LDH catalyzes the reaction:

$$
\text { Pyruvate }+\mathrm{NADH} \text { (Nicotinamide adenine dinucleotide) }+\mathrm{H}^{+} \leftrightarrow \text { Lactate }+N A D^{+}
$$

(Equation 1)

The substrates were immersed in $500 \mu \mathrm{l}\left(\mathrm{V}_{\text {assay }}\right)$ of Tris- $\mathrm{HCl}(0,1 \mathrm{M} ; \mathrm{pH} 7,1)$ containing $2,9 \mathrm{mM}$ pyruvate and 5,7 mM NADH. The reaction was monitored by a Dynamica Halo RB-10 Spectrophotometer, using a $1 \mathrm{~cm}$ length (I) glass cuvette. For each measurement, $30 \mu \mathrm{l}$ of supernatant $\left(\mathrm{V}_{\text {sample }}\right)$ were diluted in $970 \mu \mathrm{l}$ of $2,9 \mathrm{mM}$ pyruvate solution in Tris- $\mathrm{HCl}$ buffer $\left(V_{\text {cuvette }}=970 \mu \mathrm{l}+30 \mu \mathrm{l}\right)$ and absorbance at $340 \mathrm{~nm}\left(\mathrm{OD}_{340}\right)$ was measured. Note that $\mathrm{V}_{\text {assay }}$ will decrease $30 \mu \mathrm{l}$ after each measurement. The amount of LDH adsorbed was estimated from the variation of NADH concentration in the solution ( $\mu \mathrm{mol})$ versus time, following equation 2 :

$$
\mathrm{LDH}(\mathrm{mg})=(\Delta \mu \mathrm{mol} \mathrm{NADH} / \mathrm{min}) / \mathrm{U} \quad \text { (Equation 2) }
$$

Where $U$ is the specific activity of the enzyme. $U$ was experimentally characterized immediately before starting each enzymatic test, since an ageing effect was observed on LDH, with values of $U$ varying from 225,2 to $117,3 \frac{\mu \mathrm{molNADH}}{\mathrm{min} \cdot \mathrm{mg} g_{\text {prot }}}$.

In turn, the NADH moles for each time were obtained from the following expression[19]:

$$
\mu \mathrm{mol} \mathrm{NADH}\left(\mathrm{t}_{n}\right)=\frac{O D_{340}\left(t_{n}\right) \cdot \text { Vcuvette. }}{\varepsilon \cdot l} \cdot\left(n+\frac{\operatorname{Vassay}\left(t_{n}\right)}{\text { Vsample }}\right)
$$


where $\mathrm{n}$ is the number of previous measurements (i.e. $\mathrm{n}=0$ for the first measurement) and $\varepsilon$ is the molar extinction coefficient of NADH at $340 \mathrm{~nm}\left(\varepsilon=6,22 \mathrm{mM}^{-1} \mathrm{~cm}^{-1}\right)$. Combining equation 2 and 3 allows calculating the amount of functional protein on the surface.

\subsection{Protein adsorption}

The Langmuir model was used to model the protein adsorption on the functionalized surfaces. Following this model, the surface is represented as a lattice, with a certain number of effective nodes or positions that can be occupied by protein molecules. The total number of effective nodes of the surface corresponds to the Maximum Superficial Density (MSD). The Langmuir model assumes that a specific Superficial Density (SD) at equilibrium is reached for each concentration of LDH in the solution if the system is allowed to reach equilibrium.

The rate of adsorption, $\frac{d S D(t)}{d t}$, for a specific concentration of LDH is assumed to be proportional to the difference between the protein adsorbed at a given time $(\mathrm{SD}(\mathrm{t}))$ and the Superficial Density at equilibrium (SDE), and its evolution is described by equation 4:

$$
\frac{d S D(t)}{d t}=-k(S D(t)-S D E) \text { (Equation 4) }
$$

Solution of equation 4 under the initial condition $S D(0)=0$ yields:

$$
\mathrm{SD}(\mathrm{t})=\operatorname{SDE} \times\left(1-e^{-k t}\right) \quad(\text { Equation } 5)
$$

where $\mathrm{k}$ is the kinetic constant with unit minutes ${ }^{-1}$.

If the system is allowed to reach equilibrium, Langmuir model predicts that at a given temperature the coverage of the surface will be given by the equation:

$$
\theta=\frac{\text { Superficial Density Equilibrium }}{\text { Maximum Superficial Density }}=\frac{\chi \cdot[\mathrm{LDH}]}{1+\chi \cdot[\mathrm{LDH}]}
$$

(Equation 6)

Where $\chi$ is constant at a given temperature and depends on the energy involved in the adsorption process.

\subsection{Characterization of the functionalized layers}

The functionalized layers were characterized by atenuated total reflectance infrared spectroscopy (ATR), field emission scanning electron microscopy (FESEM) and fluorescence microscopy. A Nicolet iS5 infrared spectrometer, coupled to an iD5 ATR accessory, was used to characterize the biofunctional layers. The spectral range measured was $550-4000 \mathrm{~cm}^{-1}$, and 30 scans were taken for each measurement with $4 \mathrm{~cm}^{-1}$ resolution. FESEM images were obtained with an Auriga Zeiss field-emission scanning electron microscope at observation conditions $\mathrm{V}=4.0 \mathrm{kV}$. Secondary emission electrons were observed. Fluorescence was measured with a Leica DFC340FX microscope. Observation conditions: $20 x$ objective, exposition time $=425,5 \mathrm{~ms}$, gain=2,6 and gamma=1,18. A non-functionalized silicon substrate was used as control. Samples were incubated for $20 \mathrm{~min}$ in a solution that contained $1 \mathrm{mg} / \mathrm{ml}$ of fluorescein isothiocyanate (FITC) in a phosphate buffer saline (PBS) solution. After incubation, the samples were sonicated twice in PBS for 5 min. 


\section{Results and Discussion:}

The morphology and density of reactive amines of both types of biofunctional layers are shown in Figure 1. IS samples show some typical colloidal structures (figure 1A), as found in previous works[20]. In contrast, a flat and featureless surface is observed in AVS samples. Figure 1B shows the cross-sectional view of an AVS sample. The density of amino groups is higher in the AVS sample as shown by the higher fluorescence intensity (Figure $1 \mathrm{D}$ ), compared with the IS samples (Figure 1C)

\section{Adsorption kinetics}

The adsorption kinetics of LDH on both substrates was characterized by incubating the samples with a $50 \mu \mathrm{g} / \mathrm{ml} \mathrm{LDH}$ solution in Tris- $\mathrm{HCl}$ buffer for times ranging from 15 to 24 hours. Results are shown in Figure 2, for AVS (A) and for IS (B) functionalized samples. For AVS, the theoretical fitting calculated from Equation 5 is also included. The values obtained from the fitting are $S D E=5.5 \times 10^{15}$ molecules $/ \mathrm{m}^{2}$ and $\mathrm{k}=0.0069 \mathrm{~min}^{-1}$. In contrast, adsorption kinetics on IS functionalized surfaces does not show a monotonous behavior. A maximum is observed after 30 minutes of incubation $\left(1,2 \times 10^{16}\right.$ molecules $\left./ \mathrm{m}^{2}\right)$ followed by a significant decrease of the surface density of active $L D H$. These results suggest that the IS layers might be unstable after several hours immersed in a buffer.

The possible instability of the IS samples was checked by ATR spectroscopy. For that purpose, the following samples were characterized: i) silicon substrate (control), ii) as-deposited IS functionalized sample and iii) IS functionalized sample after immersion in Tris- $\mathrm{HCl}(0,1 \mathrm{M} ; \mathrm{pH}$ 6,8 ) for 24 hours. The FTIR spectra are shown in Figure 3 . It can be observed that the representative adsorption bands of silanized surfaces (Si-O-Si, of polymerized APTES at $1000 / 1250 \mathrm{~cm}^{-1}$ and $=\mathrm{NH}_{2} / \mathrm{NH}_{3}{ }^{+}$at $1500 / 1750 \mathrm{~cm}^{-1}$ ) are only present in the as-deposited functionalized sample[21]. After immersion in Tris- $\mathrm{HCl}(0,1 \mathrm{M} ; \mathrm{pH} 6,8)$, the sample shows the same spectrum as that of the silicon reference. This result supports that the IS functional layer was removed during immersion, which justified the behavior observed in Figure 2 .

\section{LDH adsorbed as a function of the LDH concentration}

The amount of LDH adsorbed on IS and AVS functionalized surfaces as a function of the LDH concentration in solution was measured by incubating the surfaces with increasing LDH concentrations ranging from 1 to $80 \mu \mathrm{g} / \mathrm{ml}$. Incubation time was fixed to 2 hours in order to characterize the adsorption on the IS despite their instability at longer immersion times, although this time does not allow the system to reach a state of complete equilibrium. The adsorbed functional LDH detected for each concentration is represented in figure 4 .

On both surfaces, the concentration of adsorbed protein steadily increases with increasing concentration of LDH until saturation is approximately reached at a concentration of about $5 \times 10^{23}$ molecules $/ \mathrm{m}^{3}$. The maximum amount of adsorbed protein (MSD), is higher on IS functionalized samples, although it could be an effect of its rougher surface compared with the AVS layer. Despite their differences, the order of magnitude of the maximum protein adsorbed on both functional layers is comparable to the theorical value of an LDH monolayer $\left(1.27 \times 10^{16}\right.$ molecules $\left(\mathrm{cm}^{2}\right)$, that is obtained by assuming an average diameter of $10 \mathrm{~nm}$ for each LDH molecule. 


\section{Covalent immobilization of LDH}

The assessment of the immobilization of LDH on the functional surfaces using glutaraldehyde as crosslinker was undertaken only on the AVS layers, due to the instability of the IS layers. As shown in Table 1, the initial surface density obtained for the sample incubated with glutaraldehyde was $3.9 \times 10^{15}$ molecules $/ \mathrm{m}^{2}$, although this value might include contributions from both adsorbed and covalently bound proteins. This value is comparable to the protein quantified on the sample incubated without glutaraldehyde under the same experimental conditions $\left(2.5 \times 10^{15}\right.$ molecules $\left./ \mathrm{m}^{2}\right)$, which serves as a control of the protein adsorbed with PBS buffer (all previous studied were performed with a Tris- $\mathrm{HCl}$ buffer). Both initial surface densities are in the range of the values obtained with the Tris- $\mathrm{HCl}$ buffer, which indicates that the change of buffer does not affect significantly the LDH adsorption or its enzymatic activity. As shown in Table 1, only the samples incubated with $2.5 \%$ glutaraldehyde were shown to keep their enzymatic activity at $8 \mathrm{~h}$ and $24 \mathrm{~h}$ which indicates the increased stability of LDH on the AVS functionalized layer upon addition of this crosslinking agent.

\section{Conclusions}

In this work, the immobilization of a functional protein on AVS and IS functionalized surfaces was investigated using lactate dehydrogenase (LDH) as a model protein. In particular, the kinetics of the process and the stability of the protein on the functionalized layers was assessed. Adsorption kinetics for AVS functionalized samples is shown to follow the theoretical Langmuir adsorption model, while the behavior observed for IS functionalized samples is more erratic and suggests that the functional layer is unstable in liquid media at long immersion times, as subsequently confirmed by ATR FTIR spectroscopy. The stability of the LDH on the AVS functionalized samples is increased by using glutaraldehyde as crosslinker. Addition of glutaraldehyde allows the detection of LDH activity even after 24 hours of immersion in a buffer. In summary, AVS biofunctional layers show a high potential for immobilizing proteins for different applications, such as implants or biosensors, while preserving the biological activity of the moieties. 


\section{Acknowledgements}

The work was funded by the Ministry of Economy and Competitiveness in Spain through Projects MAT2016-75544-C2-1-R and MAT2016-79832-R. 


\section{References}

[1] J.T. Elliott, J.T. Woodward, A. Umarji, Y. Mei, A. Tona, The effect of surface chemistry on the formation of thin films of native fibrillar collagen, Biomaterials. 28 (2007) 576-585. doi:10.1016/j.biomaterials.2006.09.023.

[2] B.G. Keselowsky, D.M. Collard, A.J. Garcia, Integrin binding specificity regulates biomaterial surface chemistry effects on cell differentiation, Proc. Natl. Acad. Sci. U. S. A. 102 (2005) 59535957. doi:10.1073/pnas.0407356102.

[3] M.H. Lee, D.A. Brass, R. Morris, R.J. Composto, P. Ducheyne, The effect of non-specific interactions on cellular adhesion using model surfaces, Biomaterials. 26 (2005) 1721-1730. doi:10.1016/j.biomaterials.2004.05.026.

[4] I.I. Slowing, B.G. Trewyn, S. Giri, V.S.-. Lin, Mesoporous silica nanoparticles for drug delivery and biosensing applications, Advanced Functional Materials. 17 (2007) 1225-1236. doi:10.1002/adfm.200601191.

[5] Y. Wang, T. Wang, P. Da, M. Xu, H. Wu, G. Zheng, Silicon Nanowires for Biosensing, Energy Storage, and Conversion, Adv Mater. 25 (2013) 5177-5195. doi:10.1002/adma.201301943.

[6] L.M. Bimbo, M. Sarparanta, E. Makila, T. Laaksonen, L. Peltonen, V.-. Lehto, A.J. Airaksinen, J. Salonen, J. Hirvonen, H.A. Santos, Mesoporous Silicon Particles as Biocompatible Drug Delivery Agents, European Journal of Pharmaceutical Sciences. 44 (2011) 129-130.

[7] H.A. Santos, L.M. Bimbo, V. Lehto, A.J. Airaksinen, J. Salonen, J. Hirvonen, Multifunctional porous silicon for therapeutic drug delivery and imaging. Current drug discovery technologies. 8 (2011) 228-49.

[8] F. Raquel Maia, S.J. Bidarra, P.L. Granja, C.C. Barrias, Functionalization of biomaterials with small osteoinductive moieties, Acta Biomaterialia. 9 (2013) 8773-8789.

doi:10.1016/j.actbio.2013.08.004.

[9] G. Wu, P. Li, H. Feng, X. Zhang, P.K. Chu, Engineering and functionalization of biomaterials via surface modification, Journal of Materials Chemistry B. 3 (2015) 2024-2042.

doi:10.1039/c4tb01934b.

[10] J.B. Brzoska, I. Benazouz, F. Rondelez, Silanization of Solid Substrates - a Step Toward Reproducibility, Langmuir. 10 (1994) 4367-4373. doi:10.1021/la00023a072.

[11] A.Y. Fadeev, T.J. McCarthy, Trialkylsilane monolayers covalently attached to silicon surfaces: Wettability studies indicating that molecular topography contributes to contact angle hysteresis, Langmuir. 15 (1999) 3759-3766. doi:10.1021/la981486o.

[12] D.G. Kurth, T. Bein, Surface-Reactions on Thin-Layers of Silane Coupling Agents, Langmuir. 9 (1993) 2965-2973. doi:10.1021/la00035a039.

[13] S.M. Martin, J.L. Schwartz, C.M. Giachelli, B.D. Ratner, Enhancing the biological activity of immobilized osteopontin using a type-1 collagen affinity coating, Journal of Biomedical Materials Research Part a. 70A (2004) 10-19. doi:10.1002/jbm.a.30052. 
[14] S.J. Xiao, M. Textor, N.D. Spencer, M. Wieland, B. Keller, H. Sigrist, Immobilization of the cell-adhesive peptide Arg-Gly-Asp-Cys (RGDC) on titanium surfaces by covalent chemical attachment, Journal of Materials Science-Materials in Medicine. 8 (1997) 867-872.

doi:10.1023/A:1018501804943.

[15] J.A. Howarter, J.P. Youngblood, Optimization of silica silanization by 3aminopropyltriethoxysilane, Langmuir. 22 (2006) 11142-11147. doi:10.1021/la061240g.

[16] R.J. Martin-Palma, M. Manso, J. Perez-Rigueiro, J.P. Garcia-Ruiz, J.M. Martinez-Duart, Surface biofunctionalization of materials by amine groups, J. Mater. Res. 19 (2004) 2415-2420. doi:10.1557/JMR.2004.0321.

[17] M. Arroyo-Hernandez, R.J. Martin-Palma, J. Perez-Rigueiro, J.P. Garcia-Ruiz, J.L. GarciaFierro, J.M. Martinez-Duart, Biofunctionalization of surfaces of nanostructured porous silicon, Materials Science \& Engineering C-Biomimetic and Supramolecular Systems. 23 (2003) 697701. doi:10.1016/j.msec.2003.09.159.

[18] M. Arroyo-Hernandez, J. Perez-Rigueiro, J.M. Martinez-Duart, Formation of amine functionalized films by chemical vapour deposition, Materials Science \& Engineering CBiomimetic and Supramolecular Systems. 26 (2006) 938-941. doi:10.1016/j.msec.2005.09.027.

[19] M. Arroyo-Hernandez, R. Daza, J. Perez-Rigueiro, M. Elices, J. Nieto-Marquez, G.V. Guinea, Optimization of functionalization conditions for protein analysis by AFM, Appl. Surf. Sci. 317 (2014) 462-468. doi:10.1016/j.apsosc.2014.08.201.

[20] I. Haller, Covalently Attached Organic Monolayers on Semiconductor Surfaces, J. Am. Chem. Soc. 100 (1978) 8050-8055. doi:10.1021/ja00494a003.

[21] D.G. Kurth, T. Bein, Thin-Films of (3-Aminopropyl)triethoxysilane on Aluminum-Oxide and Gold Substrates, Langmuir. 11 (1995) 3061-3067. doi:10.1021/la00008a035. 


\section{Figure Captions}

Figure 1: A) FESEM plan view of an IS functionalized sample. B) FESEM cross section of a functionalized AVS sample. The marker corresponds to $400 \mathrm{~nm}$ for both micrographs. Representative fluorescence images of an IS (C) and AVS (D) samples. The inset corresponds to the fluorescence image of the silicon substrate without biofunctional layer used as control.

Figure 2: Surface Density quantified by enzymatic assay at different incubation times (minutes) with a solution of $50 \mu \mathrm{g} / \mathrm{ml}$ of LDH for AVS (A) and IS (B) functionalized surfaces. In figure A, the theoretical fitting using equation 5 with values $S D E=5,5 \times 10^{15}$ molecules $/ \mathrm{m}^{2}$ and $k=0.0069 \mathrm{~min}^{-1}$ is also shown.

Figure 3: FTIR ATR spectra silicon samples functionalized by immersion silanization, either asdeposited (IS as deposited) or after immersion (IS immersed) for 24 hours in Tris- $\mathrm{HCl}$ (0,1M; pH $6,8)$. The spectrum of silicon is used as control for comparison.

Figure 4. Surface concentration (molecules $/ \mathrm{m}^{2}$ ) of active $\mathrm{LDH}$ adsorbed on the functionalized surfaces as a function of the incubation LDH concentration (molecules $/ \mathrm{m}^{3}$ ) for both IS (solid circles) and AVS (open squares) samples. 


\begin{tabular}{|c|c|c|}
\hline Immersion time (hours) & $\begin{array}{c}\text { AVS } \\
10^{15} \text { molecules } / \mathrm{m}^{2}\end{array}$ & $\begin{array}{c}\text { AVS }+2.5 \% \text { glutaraldehyde } \\
10^{15} \text { molecules } / \mathrm{m}^{2}\end{array}$ \\
\hline 0 & 2.8 & 3.9 \\
\hline 8 & 0 & 2.7 \\
\hline 24 & 0 & 1.3 \\
\hline
\end{tabular}

Table 1. Active LDH detected after immersion in PBS buffer for different times of either LDH adsorbed on AVS layers (AVS) or LDH exposed to the AVS layer in the presence of a crosslinker (AVS-2.5\% glutaraldehyde). 
Click here to download high resolution image

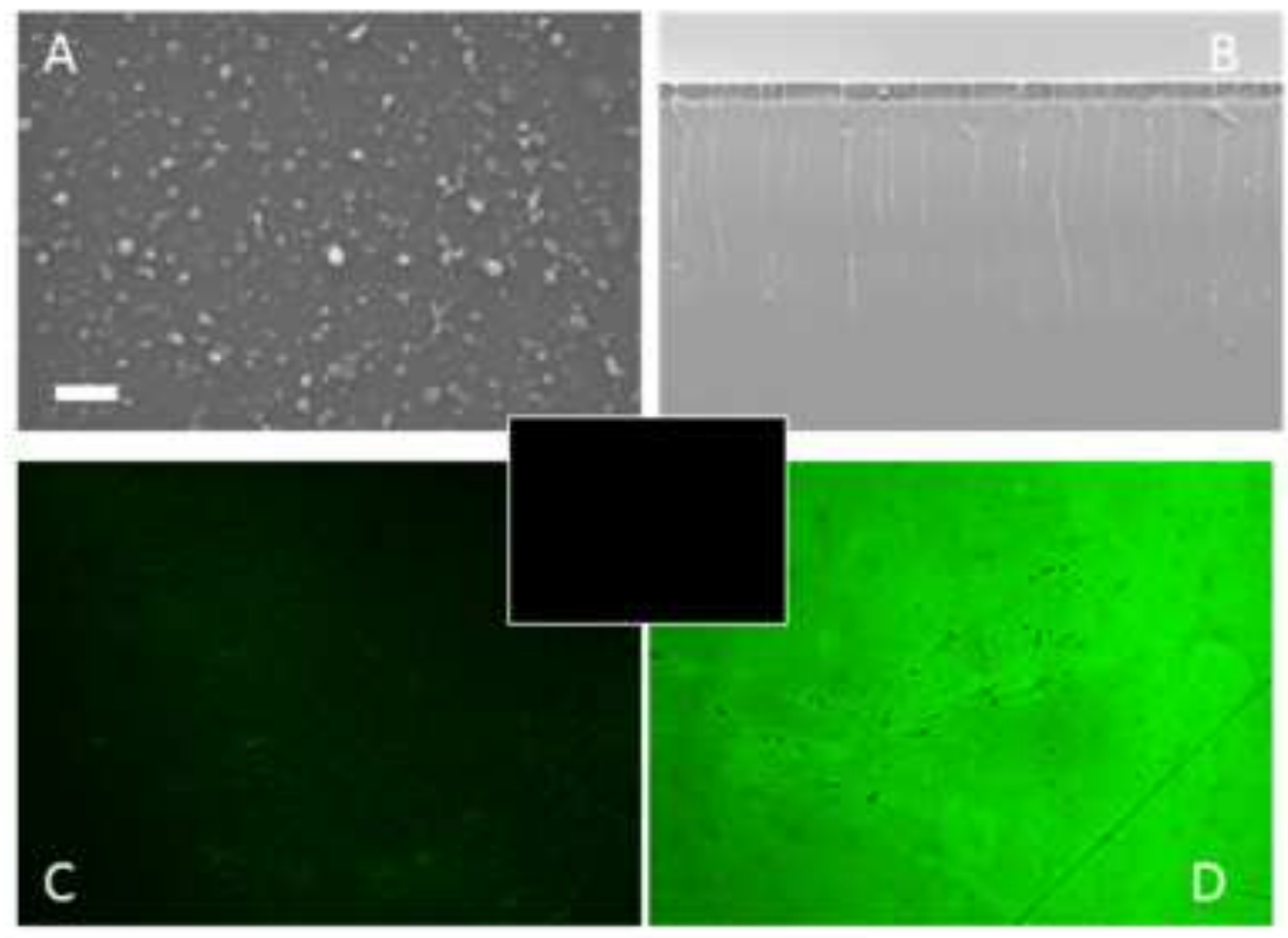

Figure 1 
Click here to download high resolution image
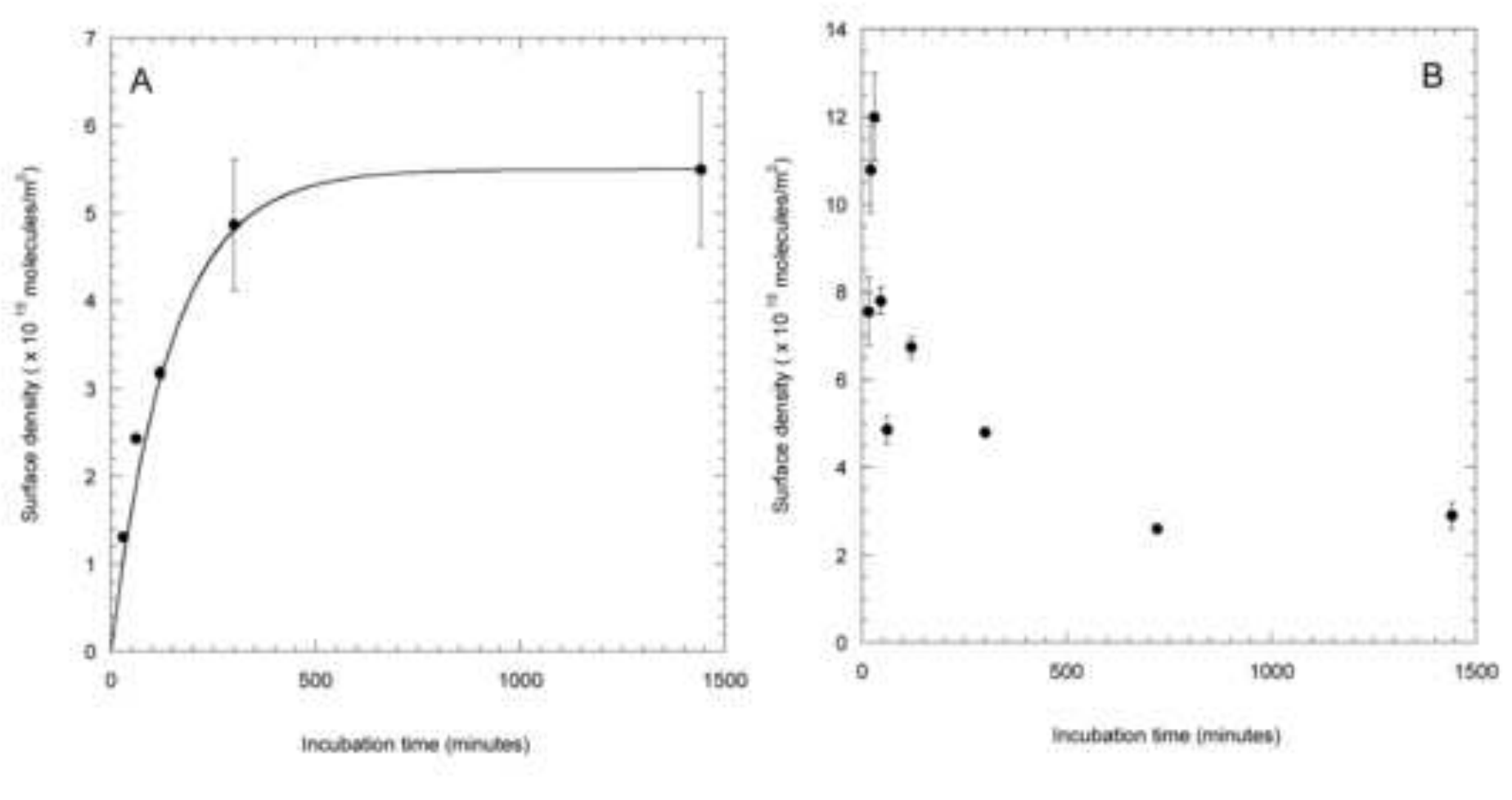

Figure 2

(1)

incubation Sme ininules

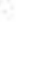

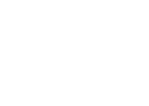

.

Figre 2

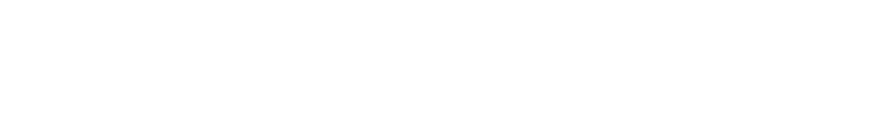


Click here to download high resolution image

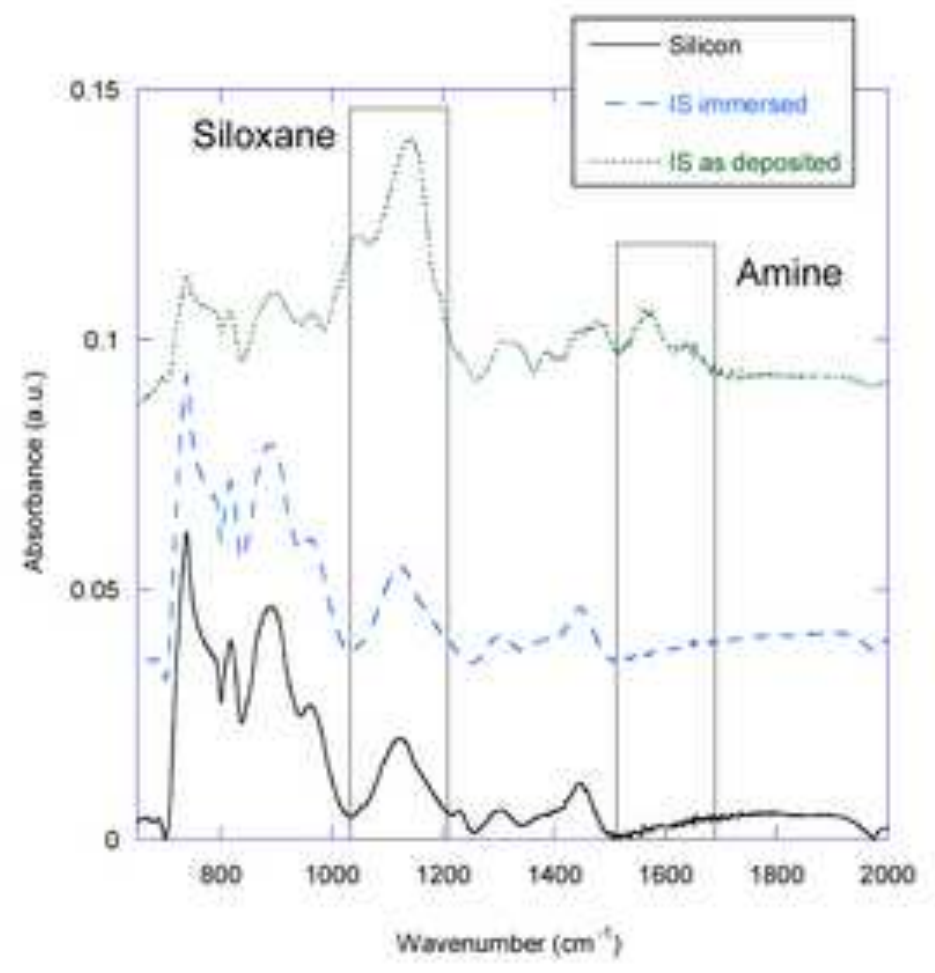

Figure 3 
Click here to download high resolution image

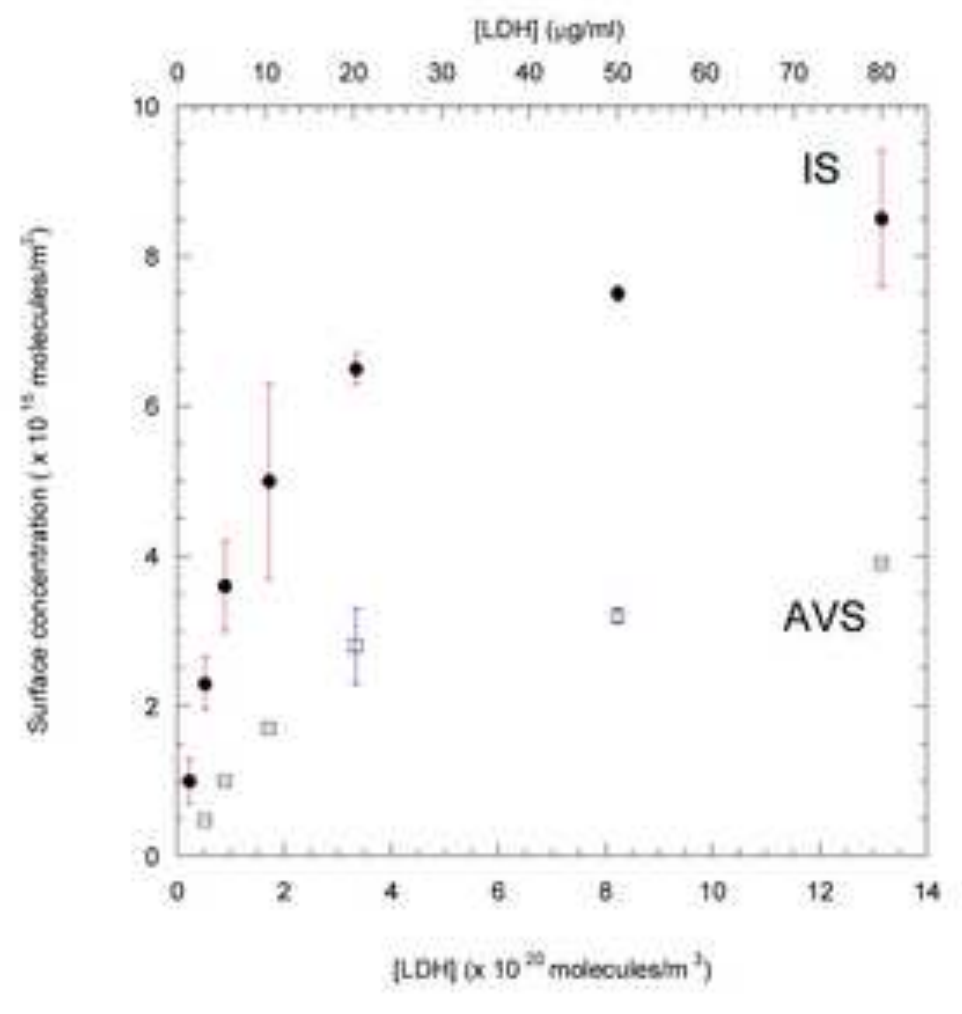

Figure 4 